https://helda.helsinki.fi

Comparison of LC-MS/MS and chemiluminescent immunoassays for immunosuppressive drugs reveals organ dependent variation in blood cyclosporine a concentrations

\title{
Becker, Anna
}

2020-09

Becker , A , Backman , J T \& Itkonen , O 2020 , ' Comparison of LC-MS/MS and chemiluminescent immunoassays for immunosuppressive drugs reveals organ dependent variation in blood cyclosporine a concentrations ' , Clinica Chimica Acta , vol. 508 , pp. 22-27 . https://doi.org/10.1016/j.cca.2020.05.007

http://hdl.handle.net/10138/329826

https://doi.org/10.1016/j.cca.2020.05.007

cc_by_nc_nd

acceptedVersion

Downloaded from Helda, University of Helsinki institutional repository.

This is an electronic reprint of the original article.

This reprint may differ from the original in pagination and typographic detail.

Please cite the original version. 


\section{Journal Pre-proofs}

Comparison of LC-MS/MS and chemiluminescent immunoassays for immunosuppressive drugs reveals organ dependent variation in blood cyclosporine

A concentrations

Anna Becker, Janne T. Backman, Outi Itkonen

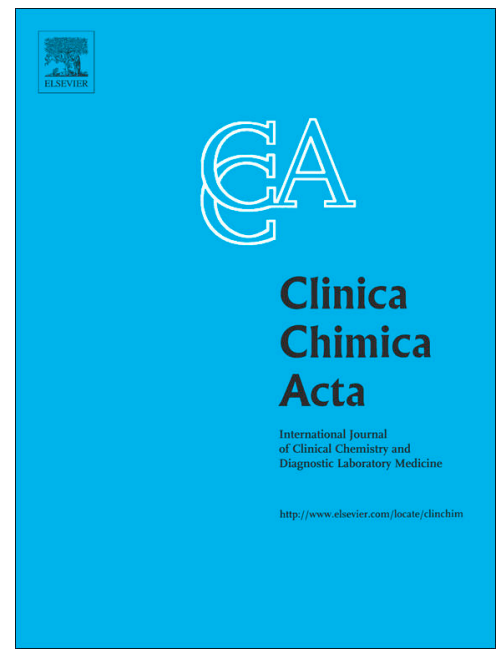

PII:

S0009-8981(20)30205-9

DOI: https://doi.org/10.1016/j.cca.2020.05.007

Reference:

CCA 16139

To appear in:

\section{Clinica Chimica Acta}

Received Date: $\quad 9$ November 2019

Revised Date: $\quad 20$ March 2020

Accepted Date: $\quad 4$ May 2020

Please cite this article as: A. Becker, J.T. Backman, O. Itkonen, Comparison of LC-MS/MS and chemiluminescent immunoassays for immunosuppressive drugs reveals organ dependent variation in blood cyclosporine A concentrations, Clinica Chimica Acta (2020), doi: https://doi.org/10.1016/j.cca.2020.05.007

This is a PDF file of an article that has undergone enhancements after acceptance, such as the addition of a cover page and metadata, and formatting for readability, but it is not yet the definitive version of record. This version will undergo additional copyediting, typesetting and review before it is published in its final form, but we are providing this version to give early visibility of the article. Please note that, during the production process, errors may be discovered which could affect the content, and all legal disclaimers that apply to the journal pertain.

(C) 2020 Published by Elsevier B.V. 


\section{Comparison of LC-MS/MS and chemiluminescent immunoassays for immunosuppressive drugs reveals organ dependent variation in blood cyclosporine A concentrations}

Anna Becker ${ }^{1}$, Janne T. Backman ${ }^{2}$ Outi Itkonen ${ }^{1}$

1. HUSLAB, University of Helsinki and Helsinki University Hospital, Helsinki, Finland.

2. Department of Clinical Pharmacology, University of Helsinki and Helsinki University Hospital, Helsinki, Finland; Individualized Drug Therapy Research Program, Faculty of Medicine, University of Helsinki, Helsinki, Finland

Abstract:

Introduction: Life-long monitoring of immunosuppressive drugs (ISDs) in blood is essential after organ transplantation. However, the ISD concentrations vary depending on the assay employed. ISDs are strongly bound to cytoplasmic proteins in erythrocytes in circulation. Therefore, the relatively rapid sedimentation of blood cells in whole blood samples may affect the results when using liquid handling robots.

Methods: We used 1115 blood samples from outpatients and ward patients with kidney $(n=373)$, liver $(n=101)$, heart $(n=29)$ and bone marrow $(n=155)$ transplant. Whole blood samples were pretreated by protein precipitation. Alternatively, the samples were hemolyzed by freezing prior to precipitation. ISDs were analyzed by a 2-plexing liquid chromatography tandem mass spectrometry (LC-MS/MS) assay and commercial chemiluminescent microparticle immunoassays (CMIA).

Results: The difference between the two sample preparation practices was negligible $(<2 \%)$. Overall, the measured ISD concentrations in patient samples were lower by LC-MS/MS than by CMIA. The difference was the largest $(20.2 \%)$ and the smallest $(9.1 \%)$ in samples from liver and from heart transplant patients, respectively.

Conclusions: CMIA overestimates blood ISD concentrations as compared to LC-MS/MS. The extent of the difference was found to be organ transplant dependent. The ISDs can be quantitated either from intact or hemolyzed blood samples.

\section{Abbreviations}

LC-MS/MS, liquid chromatography tandem mass spectrometry CMIA, chemiluminescent immunoassay 
ISD, Immunosuppressive drugs

CsA, cyclosporine A

TAC, tacrolimus

SIR, sirolimus

EVE, everolimus

TDM, therapeutic drug monitoring

HUSLAB, Helsinki University Hospital laboratory

CRM, certified reference material

$\mathrm{ACN}$, acetonitrile

$\mathrm{MeOH}$, methanol

$\mathrm{FA}$, formic acid

QA, quality assurance

rpm, revolutions per minute

RCF, relative centrifugal force

LOD, limit of detection

LOQ, limit of quantitation

$\mathrm{RE} \%$, relative error

$\mathrm{CV} \%$, coefficient of variation

$\mathrm{CE}$, collision energy

CXP, collision cell exit potential

\section{Introduction}

Human organ transplantation has been a crucial help saving lives for over 60 years [1].

Immunosuppressive drugs (ISD) are needed after transplant operation to prevent organ rejection.

Due to dose- and concentration-dependent toxicity, the therapeutic range of ISDs is narrow and monitoring of their concentrations in blood is thus a life-long procedure after organ transplantation.

Over the years, analytical methods for determination of ISDs have undergone major developments from chromatographic assays to immunoassays [2,3]. Today, liquid chromatography-tandem mass spectrometry (LC-MS/MS) is considered the golden standard, while the disadvantages of immunoassays are well recognized. For example, non-specific matrix effects and cross-reactions between immunoassay antibodies and drug metabolites can lead to overestimation of the drug concentration. This in turn can lead to critical mistreatment of the patients.

ISDs cyclosporine A (CsA), tacrolimus (TAC), sirolimus (SIR) and everolimus (EVE) are strongly bound to cytoplasmic proteins in erythrocytes. The proportion of bound ISDs has been reported to be $41-58 \%$ for CsA, $85 \%$ for TAC, 95\% for SIR and >75\% for EVE [4]. Therefore, whole blood instead of plasma specimens are routinely used for therapeutic drug monitoring (TDM) of ISDs. Protein precipitation by robotic sample handling prior to LC-MS/MS is a widely employed approach [5-7]. However, the variable and relatively rapid sedimentation of blood cells is a common challenge [6] and may result in false results. With traditional liquid handling robots, one way to mix patient samples is repeated aspirating and dispensing, which is time-consuming and sometimes inadequate. Alternatively, the samples can be mixed with a separate mixer prior to loading them into the robot and pipet the sample before sedimentation. In this approach, the extent of 
sedimentation is difficult to define. To overcome these challenges we optimized an alternative sample preparation technique by hemolyzing the samples prior to pipetting.

More than one hundred ISD monitoring samples are analyzed daily at Helsinki University Hospital laboratory HUSLAB. In addition to the relatively high amount of samples, the clinical need to obtain test results within few hours at the wards sets challenges for the monitoring laboratory. In this study, we describe the development and validation of a high throughput LC-MS/MS assay for CsA, TAC, SIR and EVE with pretreatment by protein precipitation of intact or hemolyzed blood samples, and the comparison of the LC-MS/MS assay with Abbott Architect CMIA assay for CsA, TAC and SIR employing a representative clinical sample comprising different transplant recipients.

\section{Experimental}

\subsection{Reagents and materials}

TAC, SIR, EVE and the respective stable isotope-labeled internal standards $\left({ }^{13} \mathrm{C},{ }^{2} \mathrm{H}_{4}-\mathrm{TAC},{ }^{13} \mathrm{C}_{2}\right.$, ${ }^{2} \mathrm{H}_{4}-\mathrm{EVE}$ and ${ }^{13} \mathrm{C},{ }^{2} \mathrm{H}_{3}$-SIR) were purchased from Alsachim (Illkirch Graffenstaden, France). CsA and its internal standard $\left({ }^{13} \mathrm{C}_{2}, \mathrm{~d}_{4}-\mathrm{CsA}\right.$ ) were purchased from TRC (Toronto Research Chemicals, Toronto, Canada). Certified reference materials (CRM) were purchased from Cerilliant $(1.0 \mathrm{mg} / \mathrm{mL}$ of $\mathrm{Cs} A$ in $A C N, 1.0 \mathrm{mg} / \mathrm{mL}$ of TAC in ACN and $1.0 \mathrm{mg} / \mathrm{mL}$ of rapamycin i.e. SIR in ACN, SigmaAldrich). Calibrators (Multilevel Calibrator set with six concentrations and XL variant with seven concentrations) and quality assurance (QA) samples (two concentrations) were purchased from Chromsystems Instruments and Chemicals GmbH (Gräfelfing, Germany). LC-MS-grade methanol $(\mathrm{MeOH}), 2$-propanol, zinc sulfate, ammonium formate and formic acid (FA) were purchased from Honeywell Fluka and Sigma-Aldrich. All reagents were of the highest analytical grade.

\subsection{Samples and patients}

Blood samples were drawn into EDTA-tubes (BD Vacutainer, Franklin Lakes, New Jersey, USA). We used samples from healthy volunteers $(n=4)$ and from organ transplant patients $(n=1115)$. Informed consent was obtained from all volunteers. Patient samples were analyzed as part of their diagnostic workup at Helsinki University Hospital, Helsinki, Finland. In this study, the samples were stripped of identifiers. Samples were from patients treated with CsA $(n=561)$, tacrolimus $(n=389)$ and SIR ( $n=125)$. Patients treated with CsA had undergone kidney $(n=163)$, liver $(n=63)$, bone marrow $(n=155)$ and heart $(n=12)$ transplantation. Likewise, patients treated with tacrolimus had kidney $(n=210)$, liver $(n=38)$ and heart $(n=17)$ transplants. The type of transplant of SIR treated outpatients remained unknown. In addition, 40 samples from pediatric patients treated with CsA due to bone marrow transplantation were included. 


\subsection{Instrumentation}

Samples were prepared with a Freedom Evo 150 liquid handling robot with Evoware2 Standard software (Tecan, Männedorf, Switzerland) equipped with a plate shaker and centrifuged with a Rotixa 50 RS centrifuge (Hettich Zentrifugen, Geldermalsen, Netherlands). Transcend II LX-2 multiplexing system consisting of two channels and two columns working simultaneously, Ultimate 3000 RSLC pumps, CTC-PAL autosampler and Aria OS software (Aria OS1.7) were used as the front end in the analytical system (Thermo Fisher Scientific, Waltham, USA). API4000 or API4000 QTRAP triple quadrupole mass spectrometers (AB Sciex, Toronto, Canada) with a Turbo-V electrospray ion source and Analyst software (Analyst 1.6.2) were used for detection. For chromatographic separation, we used a cyano column (XSelect HSS CN 2.5 $\mu \mathrm{m}, 2.1 \times 50 \mathrm{~mm}$, Waters) eluted with a linear gradient of $2 \mathrm{mmol} / \mathrm{l}$ ammonium formate and $0.1 \%$ formic acid in water (A) and in methanol (B). The flow rate was $600 \mu \mathrm{l} / \mathrm{min}$, runtime $3.2 \mathrm{mins}$ and column temperature $45^{\circ} \mathrm{C}$. For the MS/MS detection the next transitions were followed: $\mathrm{m} / \mathrm{z} 1220.0 \rightarrow 1203.0$ (CsA), $m / z 1227.0 \rightarrow 1210.0\left({ }^{13} \mathrm{C}_{2}, \mathrm{~d}_{4^{-}} \mathrm{CsA}\right.$ ), $\mathrm{m} / \mathrm{z} 821.5 \rightarrow 768.5$ (tacrolimus), $\mathrm{m} / \mathrm{z} 826.6 \rightarrow 773.7\left({ }^{13} \mathrm{C}^{2}{ }^{2} \mathrm{H}_{4}\right.$ - tacrolimus), $\mathrm{m} / \mathrm{z} 931.7 \rightarrow 864.7(\mathrm{SIR}), \mathrm{m} / \mathrm{z} 935.6 \rightarrow 864.7\left({ }^{13} \mathrm{C},{ }^{2} \mathrm{H}_{3}\right.$-SIR), $\mathrm{m} / \mathrm{z} 975.7 \rightarrow 908.7$ $(\mathrm{EvE})$ and $\mathrm{m} / \mathrm{z} 981.6 \rightarrow 914.8\left({ }^{13} \mathrm{C}_{2},{ }^{2} \mathrm{H}_{4}-\mathrm{EvE}\right)$. Ionization was carried out in positive ion mode with the ion source spray voltage set at $4250 \mathrm{~V}$ and the temperature at $325^{\circ} \mathrm{C}$. The injection volume was $5 \mu \mathrm{l}$ and a bypass valve was used to divert the first $60 \mathrm{sec}$ of the flow to waste and the following $36 \mathrm{sec}$ to mass detection. Four wash cycles of the syringe and the injector were performed between sample injections.

\subsection{Sample preparation}

Unless otherwise stated, all samples were carefully mixed horizontally rotating at $100 \mathrm{rpm}$ for at least 15 mins (Heidolph Unimax 2010, Schwabach, Germany). Samples were treated essentially as described previously [7]. Briefly, blood samples, calibrators and controls were pipetted (85 $\mu$ l) into the wells of a 96-deep well plate (Thermo Fisher Scientific, Waltham, USA) along with $85 \mu$ of deionized water. The plate was shaken for $30 \mathrm{sec}(1300 \mathrm{rpm})$. Then, $300 \mu \mathrm{l}$ of precipitation solution (MeOH:0.1 mol ZnSO $;$; 80:20) containing the internal standards $\left(50 \mu \mathrm{g} /{ }^{13} \mathrm{C}_{2}\right.$, d4- CsA, $20 \mu \mathrm{g} /{ }^{13} \mathrm{C}$, ${ }^{2} \mathrm{H}_{2}-\mathrm{TAC}, 7,5 \mu \mathrm{g} / \mathrm{l}{ }^{13} \mathrm{C},{ }^{2} \mathrm{H}_{3}$-SIR and $\left.15 \mu \mathrm{g} /{ }^{13} \mathrm{C}_{2},{ }^{2} \mathrm{H}_{4}-\mathrm{EVE}\right)$ was added. The plate was covered with a sealing tape (Thermo Fisher Scientific, Waltham, USA) and shaken for five mins (1300 rpm). The plate was then centrifuged for ten mins at $+4{ }^{\circ} \mathrm{C}$ at $2890 \mathrm{RCF}$ and the supernatant was used for analysis. Alternatively, samples were prepared by freezing the whole blood samples at $-80{ }^{\circ} \mathrm{C}$ ethanol bath for five mins, letting the samples thaw for $10 \mathrm{~min}$ in front of a fan or a water bath and reach room temperature, vortex-mixing them shortly, followed by pipetting of samples and reagents as above. 
To test the effect of blood cell sedimentation on measured ISD concentration, blood samples $(n=15)$ were first prepared and analyzed as routinely by mixing horizontally for $\geq 15$ min as described above. Then, the same samples were left in an upright position for ten mins to allow eventual blood cell sedimentation to occur before the analysis was repeated.

\subsection{Immunoassay of blood CsA, TAC and SIR}

Samples were analyzed by CMIA employing Architect Reagent Kit for CsA, TAC and SIR with an Abbott Architect i2000SR analyzer (Abbott Diagnostics Division, Santa Clara, USA) routinely used at HUSLAB Helsinki University Hospital. The assays were performed according to the instructions of the manufacturer with manual sample precipitation prior to the automated immunoassay, except that CsA was analyzed in duplicate and reported as the mean. The intra- and inter-assay variation of the assays were $4.8 \%$ and $\leq 13.3 \%$ for CsA, $4.1 \%$ and $\leq 6.3 \%$ for TAC and $2.8 \%$ and $\leq 4.4 \%$ for SIR, respectively.

\subsection{Validation of the LC-MS/MS assay}

HUSLAB is an accredited laboratory according to the SFS-EN ISO/IEC 17025:2005 and SFS-EN ISO 15189:2013 standards. The assay was validated following HUSLAB standard procedures. Limit of detection (LOD) was defined as the concentration corresponding to the mean intensity of 14 blank samples (sodium chloride $9 \mathrm{mg} / \mathrm{ml}$ solution, Braun) plus three SD's. Linearity and limit of quantification (LOQ) were determined by diluting calibrators with sodium chloride solution to obtain a nine-point calibration curve (CsA $3.2-1840 \mu \mathrm{g} / \mathrm{l}$, TAC $0.3-42.3 \mu \mathrm{g} / \mathrm{l}$, EVE $0.3-44.5 \mu \mathrm{g} / \mathrm{l}$ and SIR $0.3-49.0 \mu \mathrm{g} / \mathrm{l}$ ) to be measured six times on three different days. The calibration curves were derived using 1/x2 weighted linear least-squares regression. Linearity and limit of quantification (LOQ) was defined as the range and the lowest concentration, respectively, that could be measured with an inaccuracy (relative error, $\mathrm{RE}$ ) and imprecision (coefficient of variation, $\mathrm{CV}$ ) $<15 \%$. Intra-assay variation was measured by repeating two levels of QA samples 16 times in one batch and inter-assay variation was assessed by collecting five results on five different days $(n=25)$. Process efficiency was determined according to Marchi et al [8] from calculated concentrations in blood and mobile phase spiked with two concentrations of the drugs (CsA 100 $\mu \mathrm{g} / \mathrm{l}$ and $500 \mu \mathrm{g} / \mathrm{l}$, TAC, EVE and SIR $6 \mu \mathrm{g} / \mathrm{l}$ and $20 \mu \mathrm{g} / \mathrm{l})$. Accuracy was determined similarly using certified reference materials for spiking. Certified reference material for EVE was not available at the time of this study and accuracy was thus not examined. Signal suppression/enhancement i.e. matrix effect was determined by comparing the peak areas obtained from blank blood supernatant spiked with the drugs $(n=4)$ to those from mobile phase spiked with the same amount of the drugs (CsA $100 \mu \mathrm{g} / \mathrm{l}$ and $500 \mu \mathrm{g} / \mathrm{l}$, TAC, EVE and SIR $6 \mu \mathrm{g} / \mathrm{l}$ and $20 \mu \mathrm{g} / \mathrm{l}, \mathrm{n}=4$ ).

Carry-over was investigated by analyzing 50\% methanol after the highest calibrator routinely used (CsA $971 \mu \mathrm{g} / \mathrm{l}, \mathrm{TAC} 41.6 \mu \mathrm{g} / \mathrm{l}, \mathrm{SIR} 49.6 \mu \mathrm{g} / \mathrm{l}$ and EVE $44.1 \mu \mathrm{g} / \mathrm{l}, \mathrm{n}=5$ ). Linearity of sample dilution 
was evaluated by diluting high ISD concentration samples with sodium chloride solution $(9 \mathrm{mg} / \mathrm{ml})$ $1: 2,1: 4,1: 8$ and $1: 16$ (CsA) or 1:2, 1:4, and $1: 8$ (TAC) or 1:2 and 1:4 (SIR) and multiplying the measured concentration by the respective dilution factor. Stability of the ISDs in blood samples $(n=16)$ at room temperature and $a t+4{ }^{\circ} \mathrm{C}$ was studied during eight consecutive days. Samples with $<15 \%$ change from the initial concentration were considered stable.

\subsection{Statistical methods}

Methods were compared and statistically evaluated by Passing-Bablok correlation, Bland-Altman regression, paired t-test and Wilcoxon test using Analyse-it software for Microsoft Excel 4.80.9 (Analyse-it software Ltd., http://www.analyse-it.com). A p-value $<0.05$ was considered statistically significant.

\section{Results}

\subsection{Analytical and preanalytical validation of the LC-MS/MS method}

The intra- and inter-assay CVs of the LC-MS/MS assay were $\leq 3.6 \%$ and $\leq 3.5 \%$ for CsA, $\leq 4.5 \%$ and $\leq 6.2 \%$ for TAC, $\leq 5.3 \%$ and $\leq 5.0 \%$ for SIR, and $\leq 5.7 \%$ and $\leq 5.8 \%$ for EVE, respectively. Carryover of each ISD was $\leq 0.3 \%$. Patient samples with concentrations higher than the highest calibrator were linearly diluted up to 1:16 (CsA), 1:8 (TAC), and 1:4 (SIR). All ISDs in blood samples were stable for eight days at room temperature and at $+4{ }^{\circ} \mathrm{C}$. Other validation results are presented in Table 1. No interfering peaks were discovered to disturb selectivity (Figure 1).

\subsection{Comparison of sample preparation procedures}

Routinely, patient blood samples are mixed for $\geq 15$ mins prior to analysis. An alternative sample preparation procedure was to freeze the samples in a $-80^{\circ} \mathrm{C}$ ethanol bath for 5 min prior to protein precipitation. The results of frozen $(y)$ and fresh $(x)$ patient samples were compared. The CsA concentration results in patient samples $(n=95)$ correlated according to the formula $y=-0.2+1.0 x$ with a t mean difference $-0.2 \%(-0.8 \mu \mathrm{g} / \mathrm{l}, \mathrm{p}=0.960)$. Similarly, the TAC results in patient samples $(n=51)$ correlated according to $y=-0.2+1.0 x$ with a mean difference of $1.8 \%(0.2 \mu g / l, p=0.175)$. In addition, CsA $(n=15)$ and TAC $(n=15)$ blood samples were analyzed immediately after mixing and after a 10 min sedimentation time. The measured blood CsA concentrations after mixing and sedimentation were $192.1 \mu \mathrm{g} / \mathrm{L}$ (range 42 - $396 \mu \mathrm{g} / \mathrm{L}$ ) and $157.1 \mu \mathrm{g} / \mathrm{L}$ (range 32.2 - $376 \mu \mathrm{g} / \mathrm{L}$ ), respectively. Likewise, blood TAC concentrations were $8.5 \mu \mathrm{g} / \mathrm{L}$ (range $5.3-11.2 \mu \mathrm{g} / \mathrm{L}$ ) and 9.2 $\mu \mathrm{g} / \mathrm{L}$ (range $5.8-12.1 \mu \mathrm{g} / \mathrm{L}$ ), respectively (Figure 2). In contrast to CsA (mean difference $-21.0 \%$ or $-35.0 \mu \mathrm{g} / \mathrm{L}, \mathrm{p}=0.171)$, the mean difference in TAC concentration was statistically significant $(8.3 \%$ or $0.7 \mu \mathrm{g} / \mathrm{L}, \mathrm{p}<0.05)$. However, the mean difference in CsA concentration was statistically significant $(3.1 \%$ or $-5.0 \mu \mathrm{g} / \mathrm{L}, \mathrm{p}=0.009)$ when the three outliers were excluded (Figure 2 ). 


\subsection{Comparison of LC-MS/MS and CMIA}

Our newly developed LC-MS/MS method and the immunoassays were compared using 1115 patient samples (Figure 3 and Tables 2 and 3). The mean CsA and TAC results obtained by the CMIA were $14.8 \%$ and $22.9 \%$, respectively, higher than those by the LC-MS/MS assay. SIR (mean $6.2 \mu \mathrm{g} / \mathrm{L}$ by CMIA and $8.4 \mu \mathrm{g} / \mathrm{L}$ by LC-MS/MS) in patient samples $(n=125)$ correlated according to the formula CMIA $=-0.2+1.4 \mathrm{LC}-\mathrm{MS} / \mathrm{MS}$ and the mean difference was $35.8 \%(2.2 \mu \mathrm{g} / \mathrm{l})$. The difference between CsA, TAC and SIR concentrations by LC-MS/MS and CMIA within all patient groups was statistically significant $(p<0.05)$.

\section{Discussion}

Our LC-MS/MS assay is fast and suitable for simultaneous quantification of CSA, TAC, SIR and EVE in blood samples. In our laboratory, we run two Transcend II LX-2 multiplexing systems daily for ISD samples. After start-up procedures and calibration (45 $\mathrm{min}$ ), a result is completed every 1.6 min from both instruments. Samples from the hospital campus area are reported within five hours from sample draw. With the workflow of four to five batches and 100 to 200 samples daily we achieved a comparable turnaround time with another recently published studies $[4,7]$.

According to Mika et al., the most common analytical columns used in current ISD assays are C18 and phenyl-hexyl columns [9]. Cyano C18 columns are designed especially for hydrophobic bases. We found the cyano C18 column chemistry to be more suitable for analysis of hydrophobic ISDs enabling rapid elution, as well as better resolution and peak shape compared to traditional C18 columns.

Today's laboratory analysis of ISD's can roughly be divided into two groups: chromatographic separation with mass-to-charge ratio based detection (LC-MS/MS) and biological recognition of antibody-antigen immunoassays. Both are widely used. LC-MS/MS is considered the gold standard assay with high sensitivity and accuracy, but despite improved user friendliness, it is still quite challenging for the operator. Immunoassay systems may be user friendly, but they lack specificity and sometimes repeatability, and are highly dependent on the reagent supplier. We found that the CMIA overestimates ISD concentrations by $10.0-35.8 \%$. This finding is well in line with previously published studies [10,11].

In this study the smallest mean difference between the LC-MS/MS and CMIA assays was for CsA (14.8\%, n=561). Our results agree with those of Vogeser et al. using samples from 697 CsA treated patients and of Hetu et al. observing a positive average bias of $15.6 \%(n=36)[10,11]$. To the best of our knowledge, LC-MS/MS and CMIA CsA assay comparisons with different transplant cohorts have not been reported before. We found that the largest difference between LC-MS/MS and CMIA concentrations for CsA was within the liver transplant group $(25.9 \%, n=63)$ and the smallest in our limited heart transplant group $(10.0 \%, n=12)$. Enzymes like cytochromes $P 450$ 
located in the endoplasmic reticulum of hepatocytes and enterocytes metabolize hydrophobic CsA to various water-soluble metabolites (AM1, AM9 and AM4N) that are either metabolized further or excreted to bile or urine [12]. According to Wang et al., the concentrations of CsA metabolites can be particularly high in liver transplant patients [13]. The CMIA assay is considered fairly specific but still with $\leq 3.3 \%$ cross-reactivity with AM1, AM1c, AM4N, AM9 and AM19 [14]. The liver cohort samples in this study were mainly from patients with a fairly recent transplantation, when CsA metabolite concentrations can be high [13] and elimination of them may be impaired [15]. This in combination with the known CMIA cross-reactivity is likely to explain the observed discrepancy between CMIA and LC-MS/MS results within our liver transplant group. Hanwi et al. found high metabolite levels in bone marrow transplant patients. Thus, the $17.0-19.1 \%$ positive CsA bias in our kidney, bone marrow and pediatric cohorts by CMIA as compared to LC-MS/MS assay may also be due to cross-reaction of CsA metabolites in the CMIA. CsA metabolites, physiological changes affecting pharmacokinetics and time after transplantation are likely to explain these differences and should be considered when interpreting results obtained with the CMIA especially with liver transplantation patients.

All TAC treated patient samples ( $n=389$ ) gave on average $22.9 \%$ higher concentrations by the CMIA than by the LC-MS/MS assay. The smallest difference of $1.4 \mu \mathrm{g} / \mathrm{L}(20.4 \%, \mathrm{n}=210)$ was within the kidney cohort and the largest within the heart cohort $(2.2 \mu \mathrm{g} / \mathrm{l}, 28.0 \%, \mathrm{n}=17)$. Bazin et al. reported similar mean biases of $1.06 \mathrm{ng} / \mathrm{ml}, 1.55 \mathrm{ng} / \mathrm{ml}$ and $1.11 \mathrm{ng} / \mathrm{ml}$ with heart, liver and kidney transplant cohorts, respectively [17]. Others have reported positive biases of 14 to $20 \%$ as well [11,18-20]. Wallemac et al. have studied the metabolite cross-reactivity of TAC in in vitro samples [20]. Four main metabolites M-I (13-O-demethyITAC), M-II (31-O-demethyltacrolimus), M-III (15-Odemethyltacrolimus), and M-IV(12-hydroxytacrolimus) were measured by CMIA and LC-MS/MS and significant cross-reactivity was proven with M-II (94\%) and M-III (45\%).

A major mean bias of $35.8 \%$ between the LC-MS/MS and CMIA was found in our samples from patients treated with SIR $(n=125)$. Others have observed similar positive biases ranging from $14 \%$ to $41.4 \%[11,21,22]$. Schmid et al. found significant cross-reactivity of two SIR metabolites in the CMIA assay, mainly that caused by F4 (11-hydroxy-sirolimus, 37\%) and by F5 (41-O-demethylsirolimus, 20\%) [21].

Automation of sample pretreatment by liquid handling robots helps to achieve good repeatability and improved turn-around time by LC-MS/MS assays. However, whole blood sedimentation may be an issue. Our liquid handling robot is programmed to aspirate the sample from ten $\mathrm{mm}$ depth. Most of the CsA and all TAC concentrations were higher when samples were left standing for 10 mins before pipetting. This is likely to be explained by sedimentation, i.e. concentrated layer of blood cells at the depth where aspiration takes place. Sedimentation rate varies as can be seen 
from three samples with clearly decreased CsA concentration. Measured blood TAC concentration increased significantly after sample sedimentation while that of CsA increased in twelve and decreased in three samples. This shows that the extent of sedimentation can result in falsely elevated or decreased measured ISD concentration. These findings may be partly explained by a previous report according to which TAC is $85 \%$ bound to erythrocytes and CsA is only $41-58 \%$ bound $[4,23]$. Taken together, the effect of blood cell sedimentation cannot be ignored. We developed an alternative sample pretreatment procedure, where blood cells are hemolyzed in -80 ${ }^{\circ} \mathrm{C}$ prior to pipetting. ISD concentrations in frozen and fresh samples showed excellent correlation. Thus, sample hemolysis may be the method of choice when analyzing large sample batches.

\section{Conclusion}

We compared our newly developed LC-MS/MS assay with a CMIA assays for CsA, TAC and SIR in blood samples. In agreement with previous studies, we found that CMIA overestimates the ISD concentrations. Particularly for CsA, the bias varied between different transplant groups. Moreover, to overcome false ISD results caused by blood cell sedimentation, sample hemolyzation prior to pipetting may be a useful approach.

Acknowledgements

The authors thank Ms. Seija Mäki-Mikkilä and Ms. Renja Vehviläinen for expert technical assistance and healthy volunteers for sample donation.

\section{References}

[1] Barker CF, Markmann JF. Historical overview of transplantation. Cold Spring Harb Perspect Med 2013; 3:a014977.

[2] Holt DW, Johnston A, Kahan BD, Morris RG, Oellerich M, Shaw LM. New approaches to cyclosporine monitoring raise further concerns about analytical techniques. Clin Chem 2000; 46:872-874.

[3] Taylor PJ, Jones A, Balderson GA, Lynch SV, Norris RL, Pond SM. Sensitive, specific quantitative analysis of tacrolimus (FK506) in blood by liquid chromatography-electrospray tandem mass spectrometry. Clin Chem 1996; 42:279-285. 
[4] Seger C, Shipkova M, Christians U et al. Assuring the Proper Analytical Performance of Measurement Procedures for Immunosuppressive Drug Concentrations in Clinical Practice: Recommendations of the International Association of Therapeutic Drug Monitoring and Clinical Toxicology Immunosuppressive Drug Scientific Committee. Ther Drug Monit 2016; 38:170-189.

[5] Deslandes G, Gregoire M, Renaud C et al. Comparison Between an Automated and Manual Extraction for the Determination of Immunosuppressive Drugs Whole Blood Concentrations by Liquid Chromatography Tandem Mass Spectrometry. J Clin Lab Anal 2016; 30:924-929.

[6] Marinova M, Artusi C, Brugnolo L, Antonelli G, Zaninotto M, Plebani M. Immunosuppressant therapeutic drug monitoring by LC-MS/MS: workflow optimization through automated processing of whole blood samples. Clin Biochem 2013; 46:17231727.

[7] Pohanka A, Rosenborg S, Lindh JD, Beck O. Experiences from using LC-MS/MS for analysis of immunosuppressive drugs in a TDM service. Clin Biochem 2016; 49:10241031.

[8] Marchi I, Viette V, Badoud F, Fathi M, Saugy M, Rudaz S and Veuthey J L, Characterization and classification of matrix effects in biological samples analyses. J.Chromatogr.A 2010; 1217: 4071-4078

[9] Mika A, Stepnowski P. Current methods of the analysis of immunosuppressive agents in clinical materials: A review. J Pharm Biomed Anal 2016; 127:207-231. 
[10] Vogeser M, Shipkova M, Rigo-Bonnin R et al. Multicenter analytical evaluation of the automated electrochemiluminescence immunoassay for cyclosporine. Ther Drug Monit $2014 ; 36: 640-650$.

[11] Hetu PO, Robitaille R, Vinet B. Successful and cost-efficient replacement of immunoassays by tandem mass spectrometry for the quantification of immunosuppressants in the clinical laboratory. J Chromatogr B Analyt Technol Biomed Life Sci 2012; 883-884:95-101.

[12] Rosso Felipe C, de Sandes TV, Sampaio ELM, Park SI, Silva HT, Medina Pestana JO. Clinical Impact of Polymorphisms of Transport Proteins and Enzymes Involved in the Metabolism of Immunosuppressive Drugs. Transplantation Proceedings 2009; 41:14411455.

[13] Wang CP, Burckart GJ, Ptachcinski RJ et al. Cyclosporine metabolite concentrations in the blood of liver, heart, kidney, and bone marrow transplant patients. Transplant Proc 1988; 20:591-596.

[14] Wallemacq P, Maine GT, Berg K et al. Multisite analytical evaluation of the Abbott ARCHITECT cyclosporine assay. Ther Drug Monit 2010; 32:145-151.

[15] Totterman A, Lalla M, Salmela K, Hockerstedt K. Cholestasis and kidney dysfunction in liver transplant patients reduces cyclosporine metabolite excretion. Transpl Int 1992; 5 Suppl 1:190.

[16] Hamwi A, Salomon A, Steinbrugger R, Fritzer-Szekeres M, Jager W, Szekeres T. Cyclosporine metabolism in patients after kidney, bone marrow, heart-lung, and liver 
transplantation in the early and late posttransplant periods. Am J Clin Pathol 2000; 114:536-543.

[17] Bazin C, Guinedor A, Barau C et al. Evaluation of the Architect $®$ tacrolimus assay in kidney, liver, and heart transplant recipients. Journal of Pharmaceutical and Biomedical Analysis 2010; 53:997-1002.

[18] Dasgupta A, Khalil SA, Johnson-Davis KL. Analytical Performance Evaluation of a New Cobas Tacrolimus Assay on Cobas e411 Analyzer: Comparison of Values Obtained by the CMIA Tacrolimus Assay and a Liquid Chromatography Combined with Tandem Mass Spectrometric Method. Ann Clin Lab Sci 2016; 46:204-208.

[19] Saitman A, Metushi IG, Mason DS, Fitzgerald RL. Evaluation of the Waters MassTrak LC-MS/MS Assay for Tacrolimus and a Comparison to the Abbott Architect Immunoassay. Ther Drug Monit 2016; 38:300-304.

[20] Wallemacq P, Goffinet JS, O'Morchoe S et al. Multi-site analytical evaluation of the Abbott ARCHITECT tacrolimus assay. Ther Drug Monit 2009; 31:198-204.

[21] Schmid RW, Lotz J, Schweigert R et al. Multi-site analytical evaluation of a chemiluminescent magnetic microparticle immunoassay (CMIA) for sirolimus on the Abbott ARCHITECT analyzer. Clinical Biochemistry 2009; 42:1543-1548.

[22] Holt DW, Mandelbrot DA, Tortorici MA et al. Long-term evaluation of analytical methods used in sirolimus therapeutic drug monitoring. Clin Transplant 2014; 28:243-251. [23] Han K, Pillai VC, Venkataramanan R. Population pharmacokinetics of cyclosporine in transplant recipients. AAPS J 2013; 15:901-912. 
Table 1. Analytical validation results of the LC-MS/MS assays. n.d., not determined.

\begin{tabular}{|c|c|c|c|c|}
\hline & CsA & TAC & EVE & SIR \\
\hline Retention time, min & 1.4 & 1.2 & 1.3 & 1.3 \\
\hline Linear range, $\boldsymbol{\mu g} / \mathbf{I}$ & $3.2-1840$ & $1.1-42.3$ & $0.3-44.5$ & $0.3-49.0$ \\
\hline Accuracy, \% & 91.6 & 80.3 & n.d. & 96.4 \\
\hline Process efficiency, \% (mean) & 94.8 & 93.9 & 94.0 & 89.3 \\
\hline Matrix effect, \% & -10.8 & -20.7 & -11.6 & -18.5 \\
\hline LOD, $\mu$ g/l & 1.6 & 0.3 & 0.02 & 0.2 \\
\hline LOQ, $\mu$ g/l & 3.1 & 1.1 & 0.3 & 0.3 \\
\hline
\end{tabular}

Table 2. Comparison of LC-MS/MS (x) and CMIA (y) results ( $\mu \mathrm{g} / \mathrm{l})$ in CsA-treated organ transplant patient samples and mean concentrations. Mean difference is from Bland-Altman difference plot.

\begin{tabular}{|c|c|c|c|}
\hline & Passing-Bablok & Mean difference & $\begin{array}{c}\text { Mean concentration } \\
\text { LC-MS/MS / CMIA }(\mu \mathrm{g} / \mathrm{l})\end{array}$ \\
\hline All $(n=561)$ & $y=-11+1.3 x$ & $\begin{array}{c}14.8 \%, \mathrm{Cl} 13.8-15.9 \% \\
(24.9 \mu \mathrm{q} / \mathrm{l}, \mathrm{Cl} 22.6-27.3 \mu \mathrm{q} / \mathrm{l})\end{array}$ & $149.4 / 174.3$ \\
\hline Kidney (n=163) & $y=-17.1+1.3 x$ & $\begin{array}{c}19.5 \%, \mathrm{Cl} 17.1-21.8 \% \\
(29.5 \mu \mathrm{g} / \mathrm{l}, \mathrm{Cl} 25.2-33.7 \mu \mathrm{g} / \mathrm{l})\end{array}$ & $140.1 / 169.5$ \\
\hline Liver $(n=63)$ & $y=-5.5+1.3 x$ & $\begin{array}{c}25.9 \%, \mathrm{Cl} 21.6-30.3 \% \\
(47.9 \mu \mathrm{g} / \mathrm{l}, \mathrm{Cl} 39.6-56.2 \mu \mathrm{g} / \mathrm{l})\end{array}$ & $182.3 / 231.1$ \\
\hline $\begin{array}{c}\text { Bone marrow } \\
(n=155)\end{array}$ & $y=-15.5+1.3 x$ & $\begin{array}{c}17.0 \%, \mathrm{Cl} 15.0-18.9 \% \\
(33.2 \mu \mathrm{g} / \mathrm{l}, \mathrm{Cl} 28.1-38.2 \mu \mathrm{g} / \mathrm{l})\end{array}$ & $181.0 / 214.1$ \\
\hline Pediatric $(n=40)$ & $y=-29.3+1.4 x$ & $\begin{array}{c}18.5 \% \mathrm{Cl} 14.2-22.7 \%(28.1 \\
\mu \mathrm{g} / \mathrm{l}, \mathrm{Cl} 21.0-35.2 \mu \mathrm{g} / \mathrm{l})\end{array}$ & $137.5 / 165.6$ \\
\hline Heart $(n=12)$ & $y=-6.8+1.1 x$ & $\begin{array}{c}10.0 \%, \text { Cl 3.8-16.2\% (10.4 } \\
\mu \mathrm{g} / \mathrm{l}, \mathrm{Cl} 4.5-16.4 \mu \mathrm{g} / \mathrm{l})\end{array}$ & $106.7 / 117.2$ \\
\hline
\end{tabular}

Table 3. Comparison of LC-MS/MS (x) and CMIA $(y)$ results $(\mu \mathrm{g} / \mathrm{l})$ in TAC-treated organ transplant patient samples and mean concentrations. Mean difference is from Bland-Altman difference plot.

\begin{tabular}{|c|c|c|c|}
\hline & Passing-Bablok & Mean difference & $\begin{array}{c}\text { Mean concentration } \\
\text { LC-MS/MS / CMIA }(\boldsymbol{\mu g} / \mathrm{l})\end{array}$ \\
\hline All $(\mathbf{n}=\mathbf{3 8 9})$ & $\mathrm{y}=-0.2+1.2 \mathrm{x}$ & $\begin{array}{c}22.9 \%, \mathrm{Cl} 21.8-24.1 \% \\
(1.7 \mu \mathrm{g} / \mathrm{l}, \mathrm{Cl} 1.6-1-8 \mu \mathrm{g} / \mathrm{l})\end{array}$ & $7.7 / 9.4$ \\
\hline Kidney $(\mathbf{n = 2 1 0 )}$ & $\mathrm{y}=-0.2+1.2 \mathrm{x}$ & $\begin{array}{c}20.0 \%, \mathrm{Cl} 18.7-21.2 \% \\
(1.4 \mu \mathrm{g} / \mathrm{l}, \mathrm{Cl} 1.4-1.6 \mu \mathrm{g} / \mathrm{l})\end{array}$ & $7.2 / 8.6$ \\
\hline Liver $(\mathbf{n = 3 8 )}$ & $\mathrm{y}=0.3+1.2 \mathrm{x}$ & $\begin{array}{c}22.7 \%, \mathrm{Cl} 20.1-25.3 \% \\
(1.9 \mu \mathrm{g} / \mathrm{l}, \mathrm{Cl} 1.6-2.2 \mu \mathrm{g} / \mathrm{l})\end{array}$ & $8.6 / 10.5$ \\
\hline Heart $(\mathbf{n = 1 7})$ & $\mathrm{y}=1.6+1.1 \mathrm{x}$ & $\begin{array}{c}28.0 \%, \mathrm{Cl} 21.7-34.3 \% \\
(2.2 \mu \mathrm{g} / \mathrm{l}, \mathrm{Cl} 1,8-2.6 \mu \mathrm{g} / \mathrm{l})\end{array}$ & $8.3 / 10.5$ \\
\hline
\end{tabular}


Figure 1. Ion chromatograms of (A) CsA calibrator (476 $\mu \mathrm{g} / \mathrm{l})$, (B) CsA patient sample $(415 \mu \mathrm{g} / \mathrm{l})$, (C) TAC calibrator $(26.9 \mu \mathrm{g} / \mathrm{l}),(\mathrm{D})$ TAC patient sample $(11.1 \mu \mathrm{g} / \mathrm{l}),(\mathrm{E})$ SIR calibrator $(13.5 \mu \mathrm{g} / \mathrm{l}),(\mathrm{F})$ SIR patient sample $(6.7 \mu \mathrm{g} / \mathrm{l}),(\mathrm{G})$ EVE calibrator $(12.2 \mu \mathrm{g} / \mathrm{l})$ and $(\mathrm{H})$ EVE patient sample $(7.3 \mu \mathrm{g} / \mathrm{l})$. The peak width varies between 6 - 9 secs.

Figure 2. Comparison of CsA (A) and TAC (B) concentrations before and after $10 \mathrm{~min}$ sedimentation of the samples $(n=15)$. Three outliers of CsA results are shown with dotted line.

Figure 3. Passing-Bablok (A, B) and Bland-Altman (C, D) analysis of CsA (A, C; $n=561)$ and TAC results $(B, D ; n=389)$ in patient samples by LC-MS/MS and CMIA. In Bland-Altman regression analysis uniform line: mean, dotted line: $95 \%$ limit of agreement. 

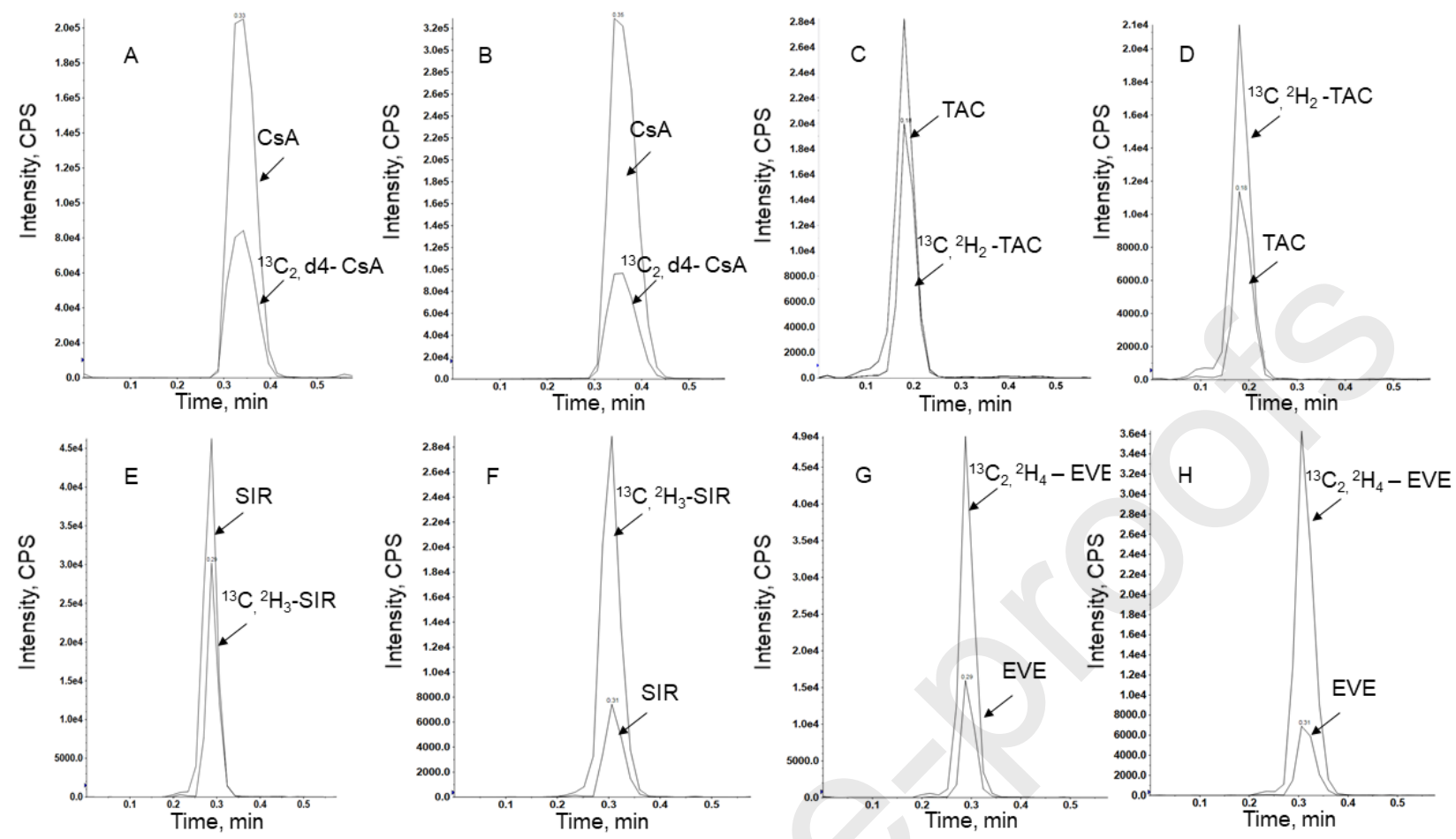


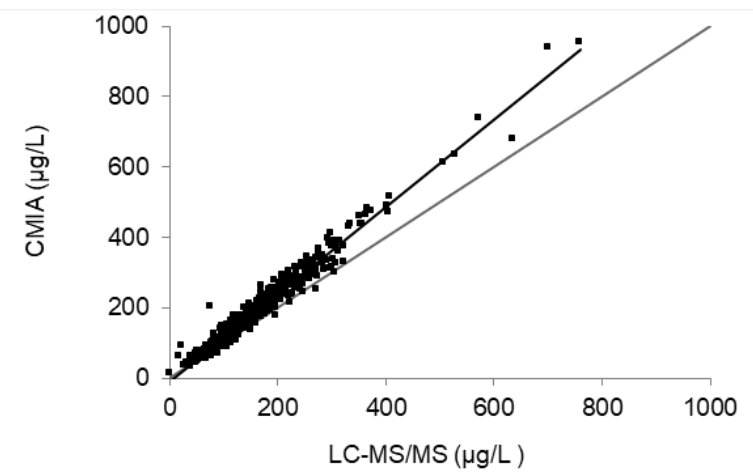

A
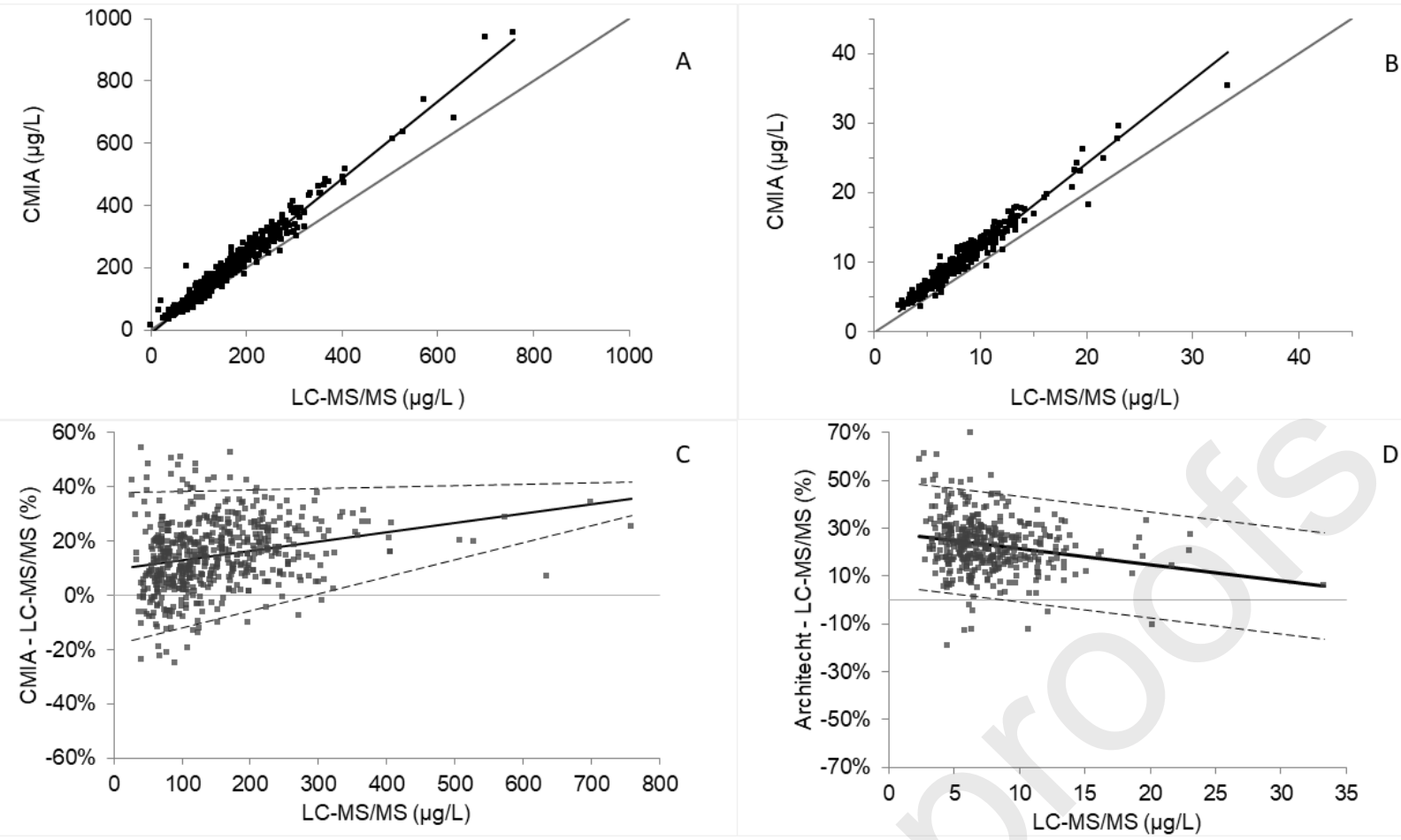


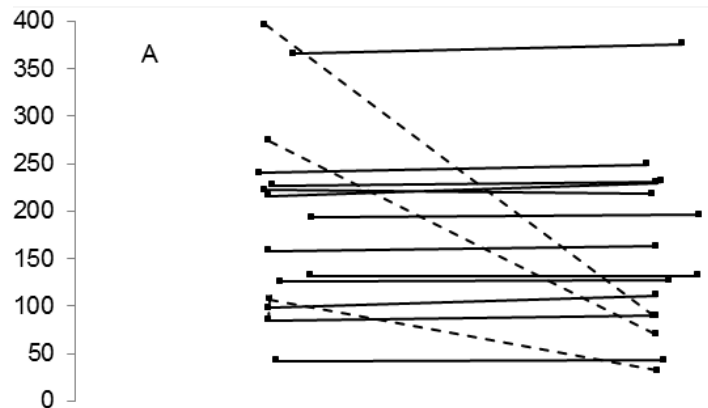

Results of fresh samples
Results after $10 \mathrm{~min}$ sedimentation

$\left.\begin{array}{r}13 \\ 12 \\ 11 \\ 10 \\ 9 \\ 8 \\ 8 \\ 7 \\ 6 \\ 5\end{array}\right] \quad$

B
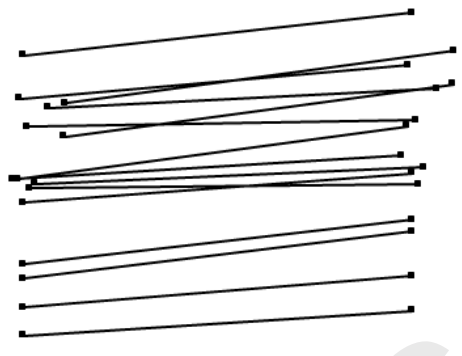

Results of fresh samples sedimentation 


\section{Highlights:}

- LC-MS/MS and chemiluminescent immunoassay results of four immunosuppressive drugs in patient samples were compared.

- Cyclosporine A concentration in blood from liver transplantation patients was found assay dependent.

- Sedimentation of blood cells effects the measured concentration.

- Hemolyzed whole blood is an alternative sample form. 
Anna Becker: Investigation, validation, Formal analysis, Writing - Original Draft. Janne Backman: Writing - Review \& Editing, Supervision. Outi Itkonen: Conceptualization, Resources, Writing Review \& Editing, Supervision, Project administration. 